\title{
SISTEM TRANSAKSI DAN PERHITUNGAN BUNGA DEPOSITO PADA BANK NAGARI CABANG PARIAMAN
}

\author{
Citra Diana, Mariani St.B Tanjung \\ Akademi Keuangan dan Perbankan Padang \\ mstbtanjung@gmail.com
}

\begin{abstract}
The aim of this research is to know whether the transaction system and the calculation of interest on Bank Nagari branch Pariaman villages have been effective in accordance with Regulation deposits contained in the legislation of Republic of Indonesia No. 10 of 1998 which represents a change of the Act No. 7 in 1992 and RI Law No. 4 of 2004 on the deposit insurance agency. This study uses qualitative descriptive method by describing the transaction and whether the system of calculation of interest on deposits at the bank branch pariaman villages have been effective. The data used are primary data in the form of interviews and secondary data in the form of the action plan of PT. Bank Nagari Branch Pariaman. The results showed that the policies and procedures and strategies implemented by PT. Bank Nagari Branch Pariaman in its deposit transaction has been effective in accordance with the minimum standards set by Bank Indonesia which is adapted to the scope of the bank's business.
\end{abstract}

Keywords: system of deposit transactions, the calculation of interest on deposits

\section{Latar Belakang}

Deposito merupakan salah satu jenis simpanan yang diperoleh dari pemupukan dana dari masyarakat. Ada beberapa bentuk simpanan yaitu simpanan dalam bentuk tabungan dan simpanan dalam bentuk deposito. Simpanan dalam bentuk tabungan dapat berupa Tabungan Siswa (Tabsis), Tabungan Masyarakat Daerah ( Tamasda ), dan Tabungan Anak Nagari ( TAN ). Sedangkan simpanan dalam bentuk deposito hanya berupa simpanan berjangka.

Deposito berjangka merupakan simpanan atas nama. Selanjutnya, Deposito yang ditarik oleh deposan sebelum jatuh tempo sebagaimana yang telah diperjanjikan, maka bank akan mengenakan pinalti pada deposan dan hak pendapatan bunga tidak diperhitungkan oleh bank atas deposito berjangka tersebut. 
Umumnya deposito berjangka diberikan hak atas bunga lebih tinggi dari bentuk simpanan lainnya, karena ada tenggang waktu tertentu dari simpanan deposito berjangka, maka akan memberikan peluang yang lebih besar pada pihak bank untuk dapat menciptakan hak kredit sesuai dengan tenggang waktu tersebut, berdasarkan ketentuan yang telah ditetapkan oleh Bank Indonesia sebagai bank sentral, tanpa mengganggu stabilitas yang telah dicapai. Penyimpanan dana di bank dibatasi oleh jangka waktu yaitu dapat dilakukan untuk periode 1 bulan, 3 bulan, 6 bulan, dan 12 bulan.

PT. Bank Nagari Cabang Pariaman juga melakukan penghimpunan dana melalui deposito untuk memporoleh dana lebih guna menunjang penyaluran sebagai produk kredit. Jumlah deposan pada PT. Bank Nagari Cabang Pariaman telah meningkat dari tahun ketahun. Bunga yang tinggi, pelayanan yang cepat, serta transaksi yang mudah merupakan usaha untuk menarik minat masyarakat agar menaruh dananya pada produk deposito.

Adapun yang menjadi permasalahan yang akan penulis bahas dalam penelitian ini yaitu :

1. Bagaimana mekanisme transaksi deposito berjangka pada PT. Bank Nagari Cabang Pariaman?

2. Bagaimana sistem perhitungan bunga deposito berjangka PT. Bank Nagari Cabang Pariaman?

\section{LANDASAN TEORI}

\section{Pengertian Bank}

Bank Umum didefinisikan oleh Undang-Undang No. 10 tahun 1998 Pasal 1 Ayat 4 tentang Perbankan sebagai berikut : " Bank yang melaksanakan kegiatan usaha secara konvensional dan atau berdasarkan prinsip syariah yang dalam kegiatannya memberikan jasa dalam lalu lintas pembayaran"

Khusus bagi bank syariah hanya menggunakan prinsip syariah. Dan saat ini selain menjalankan operasionalnya secara konvensional, bank dapat pula memilih kegiatan usaha berdasarkan prinsip syariah. Terutama setelah dikeluarkannya fatwa bunga haram dari Majelis Ulama Indonesia ( MUI ) tahun 2003.

Berdasarkan pendapat diatas, maka dapat ditarik kesimpulan, Bank adalah lembaga keuangan yang usaha pokoknya memberikan kredit dan jasa-jasa dalam lalu lintas pembayaran dan peredaran uang.

\section{Tujuan Bank}

Berdasarkan Undang - undang no 10 tahun 1998 tentang perbankan, perbankan Indonesia dalam melakukan usahanya berasaskan demokrasi ekonomi dengan prinsip kehati-hatian. Demokrasi ekonomi itu sendiri dilaksanakan berdasarkan Pancasila dan UUD 1945.

Berdasarkan asas yang digunakan dalam Undang - undang no 10 tahun 1998 tentang Perbankan, maka tujuan perbankan Indonesia adalah menunjang pelaksanaan pembangunan nasional dalam rangka meningkatkan pemerataan pembangunan dan hasil - hasilnya, 
pertumbuhan ekonomi, dan stabilitas nasional ke arah peningkatan kesejahteraan rakyat banyak.

\section{Fungsi Bank}

Fungsi utama perbankan Indonesia sesuai Undang - undang no 10 tahun 1998 tentang Perbankan adalah sebagai penghimpun dan penyalur dana masyarakat. Dana yang dihimpun dan simpanan yang dipercayakan oleh masyarakat kepada bank. Dana yang dihimpun itu kemudian disalurkan kembali oleh bank kepada masyarakat secara efektif dan efisien, dalam bentuk pemberian fasilitas kredit ataupun penyediaan dana kepada masyarakat dalam bentuk pembiayaan, baik untuk keperluan inventasi maupun keperluan modal kerja.

\section{Jenis Bank}

\section{a. Bank Umum}

Bank umum adalah bank yang melaksanakan kegiatan usaha secara konvensional dan atau berdasarkan prinsip syariah yang dalam kegiatannya memberikan jasa lalu lintar pembayaran. Sifat jasa yang diberikan adalah umum, dalam arti dapata memberikan seluruh jasa perbankan yang ada. Begitu juga dengan wilayah operasinya dapat dilakukan diseluruh wilayah. Bank umum disebut jugabank komersil (commercial bank).

b. Bank Nagari

Bank badan usaha yang menghimpun dana dari masyarakat dalam bentuk simpanan dari pihak satu proses masyarakat individu dan kelompok untuk memperoleh apa yang mereka perlukan dan inginkan untuk menciptakan, menawarkan dan dengan bebas menukarkan produk dan jasa berharga dengan orang lain.

\section{Pengertian Deposito}

Menurut Undang-undang no 10 tahun 1998 yang dimaksud dengan deposito adalah simpanan yang penarikannya hanya dapat dilakukan pada waktu tertentu berdasarkan perjanjian nasabah dengan bank.

\section{Syarat Deposito}

Seperti halnya sumber dana pihak ketiga lainnya, deposito juga mempunyai syarat-syarat yang harus diperhatikan, oleh para calon nasabah dan penyimpan dananya pada suatu bank, berikut beberapa syarat yang harus diperhatikan antara lain:

a. Deposito hanya dapat dibayar pada saat jatuh tempo di bank dalam deposito itu pertama kali dibuka

b. Deposito yang telah jatuh tempo tetapi belum ditarik maka akan diperpanjang secara otomatis menurut jangka waktu yang sama dengan suku bunga yang berlaku pada saat itu. Apabila sebelumnya ada permintaan dari deposan.

c. Bilamana deposan dinyatakan tidak kuasa menurut hukum untuk mengambil deposito atau bunganya karena meninggal dunia atau karena sebab-sebab lain maka deposito tersebut atau bunganya diserahkan kepada ahli warisnya yang sah menurut hukum.

d. Jika deposito di atas namakan dua orang atau lebih, maka: 
1) Apabila salah satu pihak meninggal dunia, maka ahli warisnya yang syah menurut hukum, dapat menerima bunga dan nominal yang tertera dalam surat deposito pada tanggal jatuh tempo.

2) Apabila salah satu melarang jumlah pembayaran tersebut kepada pihak lain, maka bank tidak akan membayar nominal dan bunganya, kecuali bilamana pihak yang bersangkutan telah menyelesaikan masalahnya.

3) Untuk pembayaran bunga deposito tidak dapat diserahkan kepada salah satu yang ditunjuk.

\section{Jenis - jenis Deposito}

Menurut Kasmir ( 2004 ) jenis deposito yaitu:

1. Deposito Berjangka

Deposito berjangka merupakan deposito yang diterbitkan dengan jenis jangka waktu tertentu. Jangka waktu deposito berjangka biasanya bervariasi mulai dari 1, 3, 6, dan 12 bulan. Deposito berjangka diterbitkan atas nama, baik perorangan maupun lembaga. Artinya didalam bilyet deposito tercantum nama seseorang atau lembaga sepemilik deposito berjangka. Penarikan bunga deposito berjangka dapat dilakukan setiap bulan atau setelah jatuh tempo atau sesuai jangka waktunya.

2. Sertifikat Deposito

Sama seperti halnya deposito berjangka, sertifikat deposito merupakan deposito yang diterbitkan dengan jangka waktu 1, 3, 6, dan 12 bulan. Hanya perbedaannya sertifikat deposito diterbitkan atas unjuk dalam bentuk sertifikat serta dapat diperjualbelikan atau dipindahtangankan kepada pihak lain. Perbedaan lain adalah pencairan bunga sertifikat deposito dapat dilakukan dimuka, baik tunai maupun non tunai, disamping setiap bulan atau jatuh tempo.

3. Deposito On Call

Deposito on call ( DOC ) merupakan deposito digunakan untuk deposan memiliki jumlah uang dalam jumlah besar dan sementara waktu belum digunakan. Penerbitan deposito on call memiliki jangka waktu minimal 7 hari dan paling lama kurang dari 1 bulan. Deposito on call diterbitkan atas nama.

Jadi, dari ketiga jenis deposito di atas memiliki keunggulan masingmasing. Dan bagi deposan yang memiliki jumlah uang yg besar lebih baik mendepositokan uangnya dalam bentuk deposito on call, karena penerbitan deposito on call lebih cepat dan bunga yang diterima lebih besar dibandingkan dengan penerbitan deposito berjangka dan sertifikat deposito.

\section{METODE PENELITIAN}

Jenis penelitian yang digunakan peneliti dalam penelitian ini yaitu deskriptif kuantitatif, penelitian ini dilakukan di PT. Bank Nagari Cabang Pariaman, yang beralamat Jl. Adinegoro Km 15 Lubuk Buaya Padang. Data yang digunakan adalah data sekunder. 
Dalam pengumpulan data dan bahan untuk melakukan penelitian ini, digunakan metode-metode pengumpulan data sebagai berikut:

1. Metode pengumpulan data

a. Studi lapangan (field research)

Pinjaman langsung ke objek penelitian dipilih untuk meneliti hasil data primer. Penelitian langsung ke lapangan ini akan dapat membantu penulis untuk melengkapi data yang diperlukan. Adapun cara riset lapangan ini adalah dengan mewawancarai pihak-pihak yang berkepentingan dalan hal ini adalah perusahaan atau instansi yang terkait.

b. Studi ke perpustakaan (library research)

Penelitian yang dilakukan ke perpustakaan beberapa buku buku ilmiah dan tulisan-tulisan yang berhubungan dengan pembahasan yang dilakukan.

\section{HASIL DAN PEMBAHASAN}

1. Mekanisme Transaksi Deposito Berjangka

Pada PT. Bank Nagari Cabang Pariaman, hanya ada satu jenis deposito yang ditawarkan yaitu deposito berjangka. Artinya jangka waktu deposito mulai dari 1, 3, 6, dan 12 bulan. Sebelum bertransaksi pada deposito, terlebih dahulu harus mempunyai rekening deposito di PT. Bank Nagari Cabang Pariaman. Persyaratan untuk membuka rekening deposito pun cukup mudah dan cepat.

Untuk proses pembukaan deposito berjangka antara Bank Nagari dengan Bank Nagari Cabang lainnya secara umum sama. Akan tetapi keunggulan dari PT. Bank Nagari Cabang Pariaman dengan bank lain dalam hal pembukaan deposito berjangka prosesnya tidak memakan waktu lama, pelayanan cepat, serta penjelasan syarat dan ketentuan mudah dipahami.

Selain itu besarnya pinalti apabila nasabah melakukan penarikan deposito berjangka sebelum tempo yang ditentukan maka PT. Bank Nagari Cabang Pariaman akan mengenakan pinalti sebesar Rp. 100. 000, dari pokok deposito sudah termasuk biaya administrasi. Pinalti yang dikenakan lebih kecil dari bank umum lain. Itulah mengapa banyak yang menjadi deposan PT. Bank Nagari Cabang Pariaman hingga keuntungan dari produk deposito berjangka mengalami peningkatan dari tahun ketahun.

2. Sistem Perhitungan Bunga Deposito Berjangka PT. Bank Nagari Cabang Pariaman.

Untuk perhitungan bunga deposito hampir semua rumus yang digunakan untuk setiap bank, baik bank umum maupun Bank Nagari sama. Yang membedakan hanya terletak pada kebijakan pemberian bunga deposito.

Ada beberapa ketentuan dana deposito serta bunga yang diperoleh pada PT. Bank Nagari Cabang Pariaman yaitu:

a. Untuk nominal Rp. 1.000.000,00 - Rp. 7.500.000,00 bunga yang diperoleh untuk jangka waktu 1, 3, 6, 12 bulan $6,25 \%$ 
b. Untuk nominal lebih dari Rp. $7.500 .000,00$ bunga yang diberikan tetap sama namun terkena pajak $20 \%$

atau dapat juga dilihat dalam bentuk tabel sebagai berikut:

Tabel 1.

Bunga Deposito

\begin{tabular}{|l|l|l|l|l|l|l|}
\hline \multirow{2}{*}{ No } & \multirow{2}{*}{$\begin{array}{l}\text { Nominal } \\
\text { Deposito }\end{array}$} & \multicolumn{4}{|c|}{ Jangka Waktu } & \multirow{2}{*}{ Pajak } \\
\cline { 3 - 6 } & & 1 bulan & 3 bulan & 6 bulan & 12 bulan & \\
\hline 1 & $1 \mathrm{jt}-7,5 \mathrm{jt}$ & $6.25 \%$ & $6.25 \%$ & $6.25 \%$ & $6.25 \%$ & - \\
\hline 2 & $>7,5 \mathrm{jt}$ & $6.25 \%$ & $6.25 \%$ & $6.25 \%$ & $6.25 \%$ & $20 \%$ \\
\hline
\end{tabular}

Untuk rumus perhitungan bunga deposito berjangka yaitu:

\section{Bunga $=\underline{\text { Nominal } x \text { tingkat bunga } x \text { hari bunga }}$}

\section{0 hari}

Terdapat rumus lain yang digunakan untuk menghitung bunga, bisa mencari bunga sehari dulu baru mencari bunga secara keseluruhan hari deposito.

\section{Bunga Bulan $=\underline{\text { nominal deposito } x \text { tingkat bunga }}$}

\section{2 bulan}

Hari keseluruhan bunga = bunga sehari $\mathrm{x}$ hari bunga

Hasil yang diperolehpun sama, hanya untuk mempermudah agar lebih dimengerti. Agar lebih mengerti tentang praktik perhitungan maka ada 2 contoh perhitungan, sebagai berikut:

a. Seorang nasabah mendepositokan dana di PT. Bank Nagari Cabang Pariaman sebesar Rp. 4.000.000,00 selama 1 bulan pada bulan maret, maka bunga yang diperoleh adalah

(4.000.000 x 6,25\% ) / 12 maka bunga yang diperoleh sebesar Rp. 20.833.

Contoh lain yang mungkin bisa dimengerti dan berbeda dengan contoh di atas adalah sebagai berikut:

b. Seorang nasabah mendepositokan dana di PT. Bank Nagari Pariaman sebesar Rp. 8.000.000 selama 3 bulan pada bulan maret, maka bunga yang diperoleh adalah:

Bunga $=(8.000 .000 \times 6,25 \%) / 12=$ Rp. 41,666

Pajak $=20 \% \times 41,666$

$$
=\text { Rp. } 8,333
$$

Bunga bersih $=41,666-8,333=$ Rp. 33,333 maka bunga yang diperoleh sebesar Rp. 33,333

Untuk contoh b karena dana yang didepositokan lebih dari Rp.7.500.000,00,-

Bunga $=(7.500 .000,00 \times 6,25 \%) / 12=3,906$

Pajak $=20 \% \times 3,906=78,12$

Bunga bersih $=78,12-3,906=$ Rp. 78.124

Maka bunga yang diperoleh dipotong pajak sebesar 20\% maka bunga bersih yang diperoleh setelah potong pajak sebesar Rp. 78.124

Dengan ini maka nasabah bisa mengetahui berapa besar bunga yang diperoleh apabila mendepositokan dana pada PT. Bank Nagari Pariaman. 
Karena pada PT. Bank Nagari Pariaman hanya ada produk deposito berjangka, maka perhitungan bunga memakai rumus di atas.

\section{KESIMPULAN DAN SARAN}

1. Kesimpulan.

Dengan penjelasan serta pembahasan tentang mekanisme transaksi dan perhitungan deposito, maka dapat disimpulkan:

a. Mekanisme transaksi deposito berjangka pada PT. Bank Nagari Cabang Pariaman telah berjalan sesuai dengan prosedur yang telah ada dari mulai pembukaan rekening deposito hingga pencairan deposito.

b. Pemberian bunga deposito pada PT. Bank Nagari Cabang Pariaman telah sesuai dengan ketentuan-ketentuan yang ditetapkan antara besarnya nominal dana yang didepositokan dengan besarya pemberian bunga. Pada perhitungan bunga deposito berjangka di PT. Bank Nagari Cabang Pariaman telah sesuai menggunakan rumus yang ditetapkan dan nominal bunga yang diperoleh sesuai dengan besarnya pemberian bunga.

2. Saran

Pada Bank Nagari Cabang Pariaman mekanisme transaksi deposito sudah sesuai dengan prosedur yang ada. Kemudahan pembukaan rekening deposito hingga pencairan deposito membuat banyak nasabah ingin membuka rekening deposito pada PT. Bank Nagari Cabang Pariaman. Akan tetapi untuk meningkatkan produk deposito bisa dilakukan dengan memberikan variasi produk deposito. Membuka produk deposito lain seperti sertifikat deposito atau deposito on call bisa menambah pilihan nasabah

\section{DAFTAR PUSTAKA}

Afriyeni, A. (2017). Profitabilitas Bank Perkreditan Rakyat Di Kota Padang Di Tinjau Dari Rasio Likuiditas. Jurnal Benefita: Ekonomi Pembangunan Manajemen Bisnis Dan Akuntansi. Volume 2. No. 1. http://doi.org/10.22216/jbe.v2i1.2104

Afriyeni, A. Fernos, J (2018). Analisis Faktor-Faktor Penentu Kinerja Profitabilitas Bank Perkreditan Rakyat (BPR) Konvensional Di Sumatera Barat. Jurnal Benefita: Ekonomi Pembangunan Manajemen Bisnis Dan Akuntansi. Volume 3. No. 3. http://doi.org/10.22216/jbe.v3i3.3623

Hasibuan, Melayu S P.2005.Dasar-Dasar Perbankan.Yogyakarta

Iswandono.1999.Uang Dan Bank.Yogyakarta:BPFE 
Ikbal, M., \& Marlius, D. (2017). Pengaruh Jumlah Taksiran Dan Uang Pinjaman Terhadap Laba Bersih Pada PT. Pegadaian (UPC) Gurun Laweh. https://doi.org/10.31227/osf.io/uch4a

Fernos, J (2017). Analisis Rasio Profitabilitas Untuk Mengukur Kinerja (Studi Kasus Pada PT. Bank Pembangunan Daerah Provinsi Sumatera $\begin{array}{lllll}\text { Barat. Jurnal Pundi. Vol } & 01 .\end{array}$ https://doi.org/10.31575/jp.v1i2.25

Kasmir. 2002.Bank Dan Lembaga Keuangan Lainnya.Edisi ke-6.Penerbit PT.Raja Grafindo Persada.

Mulyadi.1993.Akutansi Sumber Dana Bank.Jakarta:Institut Bankir Indonesia

Sinungan,Muchdasyah.2000.Manajemen Dana Bank.Edisi Kedua Cetakan Keempat.Bandung:Bumi Aksara

Slamet,Dahlan.2005.Manajemen Lembaga Keuangan.Kebijakan Moneter Dan Perbankan Edisi Kelima Jakarta:FE UI

Undang-undang no 10 Tahun 1998 Tentang Perbankan.Jakarta:Sinar Gravika.1999

Widayati, R. (2019). Penerapan Sistem Pembagian Pendapatan Pada Bank Mudharabah Nagari Syariah Cabang Padang. https://doi.org/10.17605/OSF.IO/BC3R5 